\title{
A Digital Management System of Cow Diseases on Dairy Farm
}

\author{
Lin $\mathrm{Li}^{1}$, Hongbin Wang ${ }^{2}$, Yong Yang ${ }^{3}$, Jianbin $\mathrm{He}^{1}$, Jing Dong ${ }^{1, *}$, and Honggang Fan $^{2}$ \\ ${ }^{1}$ School of Animal Husbandry and Veterinary Medicine, Shenyang Agricultural University, \\ 110866 Shenyang, P.R. China \\ lilin619619@yahoo.com.cn, dongjing9834@yahoo.com.cn \\ ${ }^{2}$ School of anima Medicine 1, Northeast Agricultural University, \\ 150030 Harbin, P.R. China \\ ${ }^{3}$ School of Information and Electrical Engineering, Shenyang Agricultural University, \\ 110866 Shenyang, P.R. China
}

\begin{abstract}
A digital management system of cow diseases is presented in this paper, which based on standardization disease management framework. It can manage dairy cow disease from each stage including cow file creation, routine monitoring, disease prevention and control. Integrate electronic medical records was set up, which based on medical records include cow basic information and routine monitoring results and disease prevention information and can implement statistical analytic function of disease rate and guide cow immunization. The Unique numbers and integrated medical records information of every cow will lay the foundation for food of animal origin traceability. This system includes four subsystems, cow basic information management subsystem, cow individual health monitoring and evaluation subsystem, cow electronic medical records subsystem and cow disease prevention and control subsystem. With the help of system analysis and software design techniques, it is can manage cow disease on dairy farm effectually.
\end{abstract}

Keywords: Digital management, cow diseases, dairy farm.

\section{Introduction}

In china, dairy production specifically in general is of great importance. There has been a good trend for the development of cow husbandry in recent years. However, milk and meat yield per cow tend to remain low, although total production has increased, mainly due to increased cow numbers. The reasons are manifold but the main is various kinds of diseases that are ineffective management due to short of disease system of administration. In some economically developed countries, information technology (IT) continues to develop rapidly and is widely and successfully employed in the dairy cattle sector. Large central computers with millions of cow files, operated by cow diseases control program, have been operational for decades to provide the farmers with information (Xiong B H, et al., 2005; Nuthall, P, et al., 2004; Warren, M, et al.2000). Data

\footnotetext{
* Corresponding author.
} 
bases are also increasingly used in a decentralized way on low cost personal computers, by farmers and farm advisors, in the so-called management information systems. Veterinary practitioners use such systems to support a new methodology for safeguarding cow health under the prevailing intensive production conditions (Vaarst, M, et al., 2006; Hamilton, C, et al., 2006; Nyman, A, et al.2007). In this paper, we built a digital management system of cow diseases that combining computer technology, network technology and information management, it will prevent and control disease effectually and promote the economy of dairy farm significantly.

\section{Design of the Digital Management System of Cow Diseases}

The digital management system of cow diseases is a network system that combines $\mathrm{B} / \mathrm{S}$ structure and ASP techniques. B/S structure has low requirement for user's hardware with high degree of information resource of expansibility. The users' working interface is realized by the universal browsers and their needs can be satisfied clicking

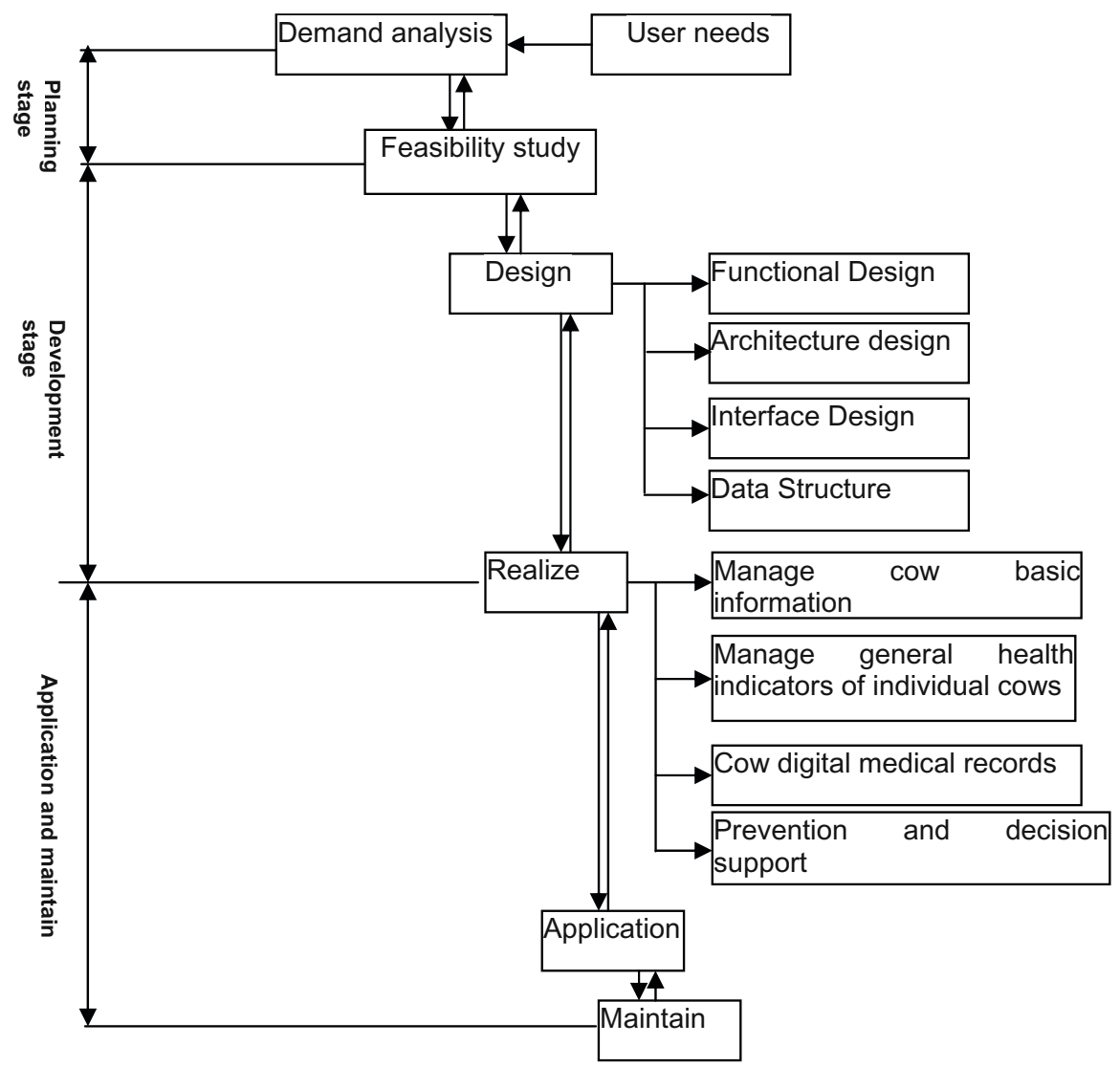

Fig. 1. The route of the digital management system of cow diseases 


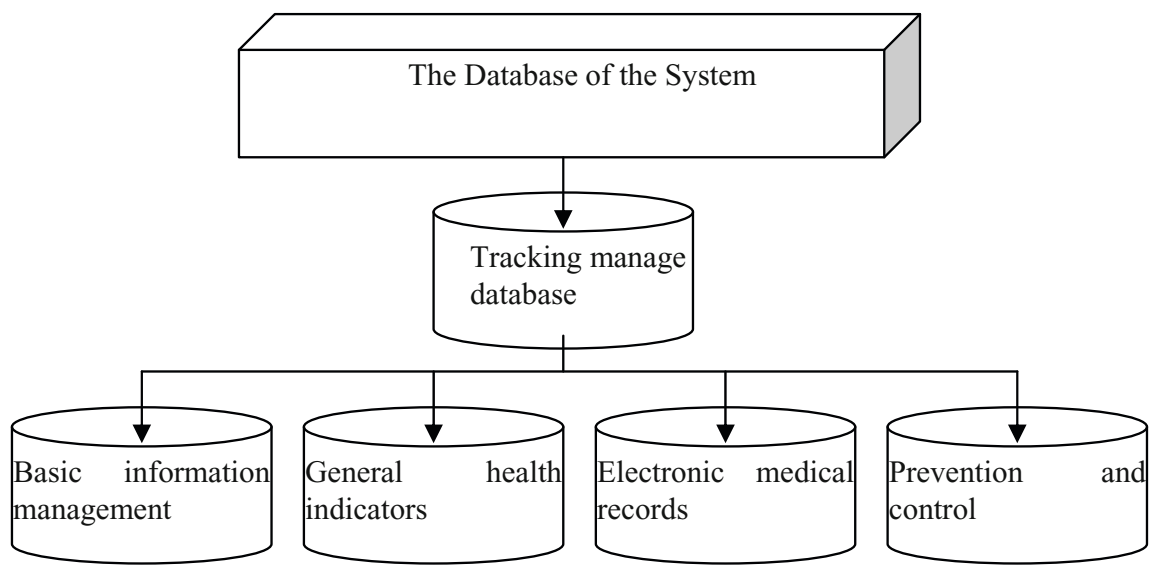

Fig. 2. The Database of Cow Disease Digitization Management Platform

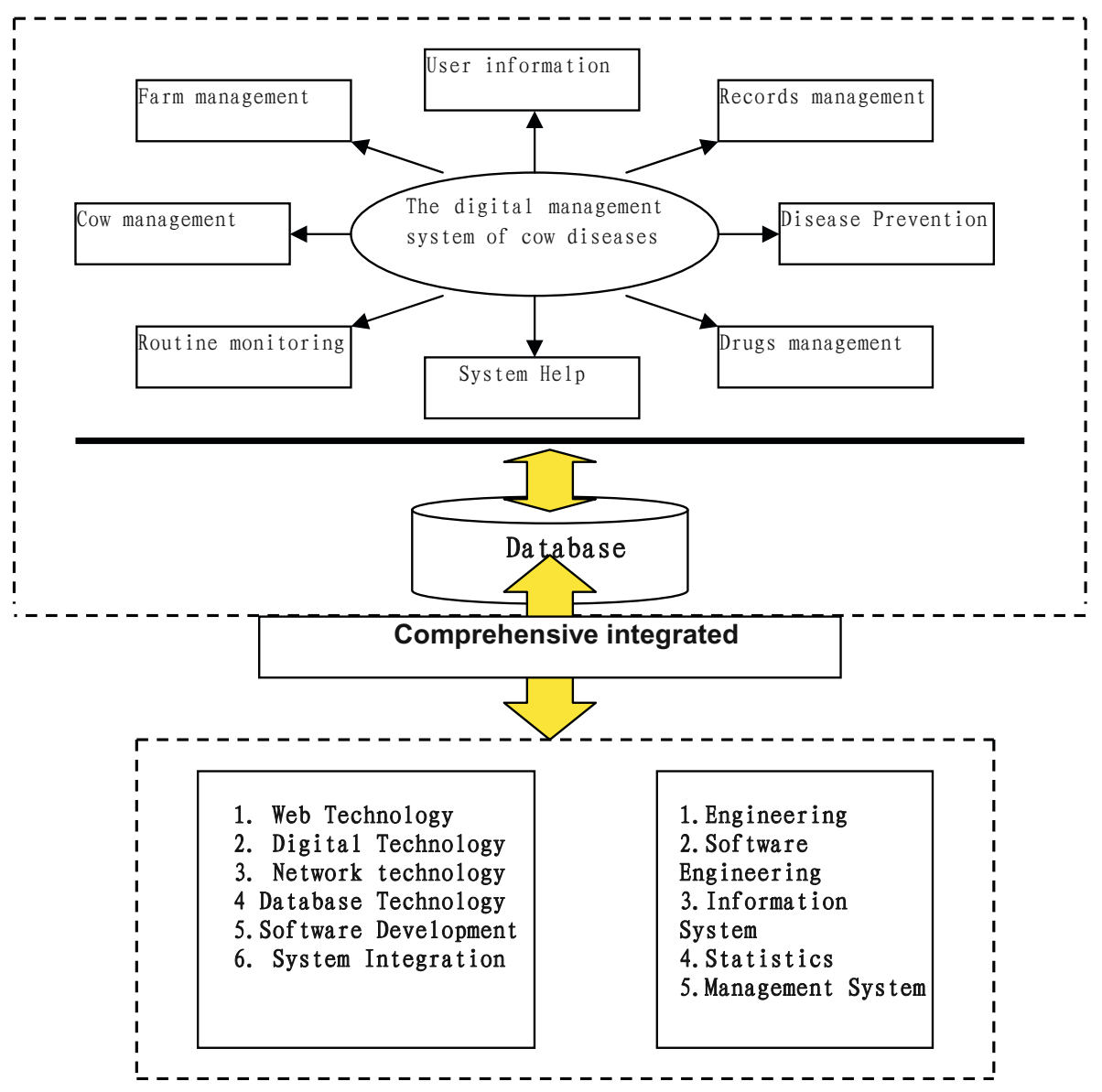

Fig. 3. Frame of the system 
the mouse. The main working logic realized in the server with little of it done in browser. The load in the client is simplified, decreasing the cost and working load of system maintenance in this way. It possesses five structures which are data storage layer, data service layer, safe layer, business layer and user service layer. Every layer was design by Object Oriented, duplication of groupware make data layer, safe layer and business layer flexibility. The route of the system is shown in fig.1.

The system working platform adopts window 2003 server and database utilizes SQL Server2000. The designing method uses New Orleans designing mode, which classifies designs of database into four stages: analysis of needs, conceptual design, logical design and physical design. The Database of Cow Disease Digitization Management Platform is shown in fig.2.

It is a cow tracking Management Database, which includes cow basic information management database, cow general health indicators database, cow electronic medical records management database, cow disease prevention and control database. The digital management system construction framework is a whole of many elements, which integrates information collection, communication, possessing and so on, the purpose is to provide technology and organization of cow information and security. Its main function is to collect information of cow diseases, processing, storage and analysis by feedback. The frame of system is shown in fig. 3 .

\section{Implement and Function of the System}

This system includes four subsystems, which are cow basic information management subsystem, cow individual health monitoring and evaluation subsystem, cow electronic medical records subsystem and cow disease prevention and control subsystem.

These functions were come true that including dairy farm management, cow information management, routine monitoring, medical records management, disease prevention, drug management, user information management and statistical analysis. The function of system is shown in fig.4.

Standardization and applicable disease management framework has been built. It can manage dairy farm from each aspects including cow files creation, routine monitoring, disease prevention. Since the cow come in dairy farm, this system creates cow record and monitor cow health and evaluate abnormal index in whole breed management process dynamically.

Integrate electronic medical records that can guide routine monitoring and Support decision making by statistical analysis was set up. It based on medical records include cow basic information and routine monitoring results and disease prevention information. Digitalization management of electronic medical records implements statistical analytic function of disease rate and can guide cow immunization and helminthicide. It is the core of cow disease control and supports user to obtain complete and precise information of disease and supply clinical decision service. The Unique numbers and integrated medical records information of every cow will lay the foundation for food of animal origin traceability. Cow routine monitoring content is divided to routine inspection, physiology monitoring, performance monitoring, ketone monitoring, 


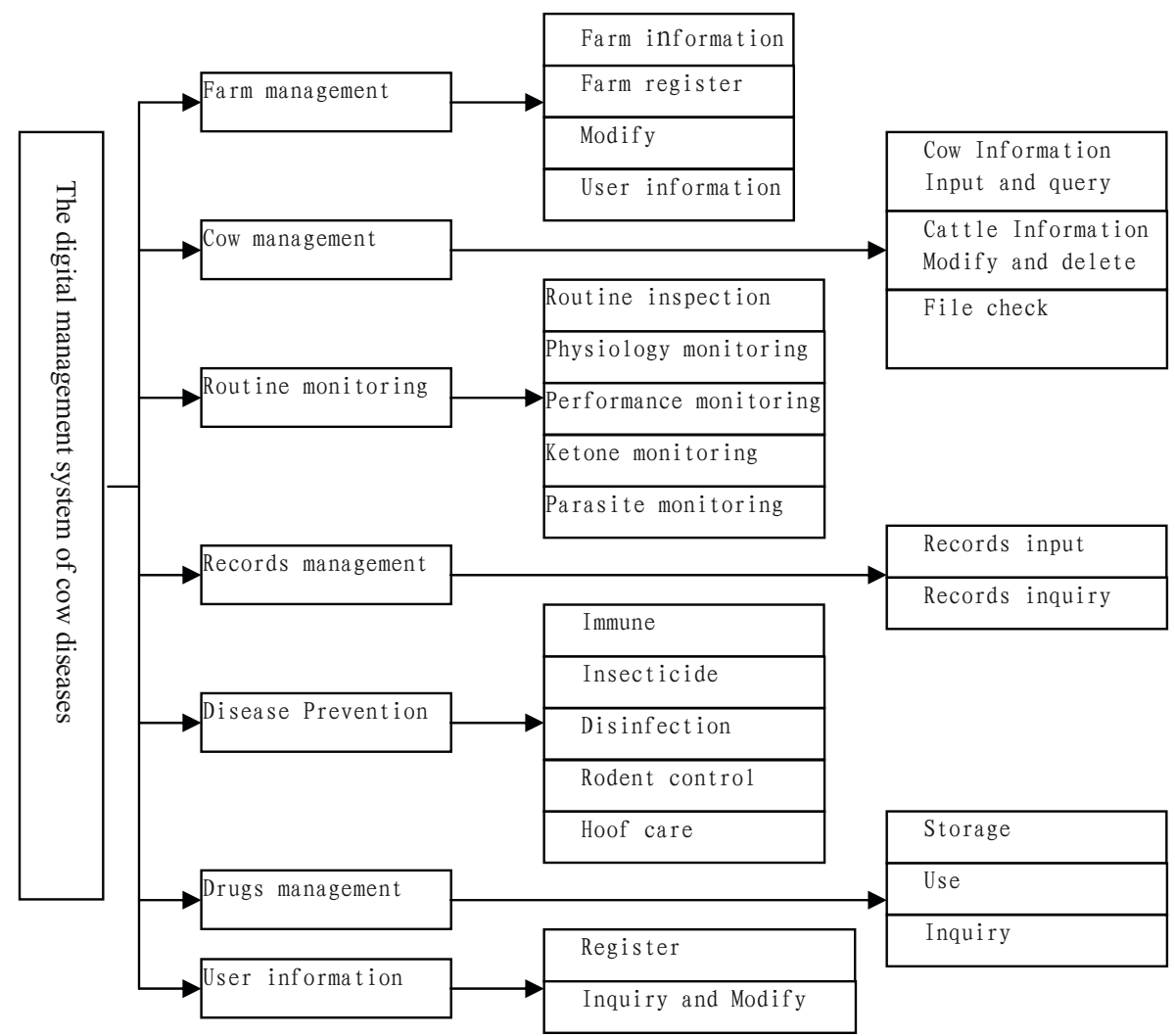

Fig. 4. Function of the digital management system of cow diseases

parasite monitoring by analyzing causative agent and protective step of cow diseases, it settles foundation for cow health management.

\section{Conclusion}

The digital management system of cow diseases that was created implements routine monitoring standardization, applicable and integrity electron case file, disease prevention systematization. It can manage dairy cow disease from each stage and ensures cow health and raises output and quality of milk, settle the foundation of foods of animal origin traceability. With the help of system analysis and software design techniques, it is can manage cow disease on dairy farm effectually. These will bring evident economic returns.

\section{Acknowledgement}

Funding for this research was in part provided by china postdoctoral science foundation (NO.20090461189), the postdoctoral fund of Shenyang Agricultural University, 
Research fund for young teachers of Shenyang Agricultural University, Dr. Start Fund of Liaoning Province, P. R. China. The authors are grateful to the Shenyang Agricultural University for providing conditions with finishing this research.

\section{References}

1. Xiong, B.H., Qian, P., Luo, Q.Y., Lv, J.Q.: Design and realization of solution to precision feeding of dairy cattle based on single body status. J. Transaction of the Chinese Society of Agricultural Engineering 21, 118-123 (2005)

2. Nuthall, P.: Case studies of the interactions between farm profitability and the use of a farm computer. J. Comput. Electron. Agric. 42, 19-30 (2004)

3. Warren, M., Soffe, R., Stone, M.: Farmers, computers and the internet: a study of adoption in contrasting regions of England. J. Farm Manage. 11, 665-684 (2000)

4. Vaarst, M., Bennedsgaard, T.W., Klaas, I., Nissen, T.B., Thamsborg, M., Ostergaaerd, S.: Development and daily management of an explicit strategy of nonuse of antimicrobial drugs in twelve Danish organic dairy herds. J. Dairy Sci. 89, 1842-1853 (2006)

5. Hamilton, C., Emanuelson, U., Forslund, K., Hansson, I., Ekman, T.: Mastitis and related management factors in certified organic dairy herds in Sweden. J. Acta Vet. Scand. 48, 2530 (2006)

6. Nyman, A., Ekman, T., Emanuelson, U., Gustafsson, A.H., Holtenius, K., Persson Waller, K., Hallen Sandgren, C.: Risk factors associated with the incidence of veterinary-treated clinical mastitis in Swedish dairy herds with a high milk yield and a low prevalence of subclinical mastitis. J. Prev. Vet. Med. 78, 142-160 (2007)

7. Nodtvedt, A., Bergvall, K., Emanuelson, U., Egenvall, A.: Canine atopic dermatitis: validation of recorded diagnosis against practice records in 335 insured Swedish dogs. J. Acta Vet. Scand. 48, 1-7 (2006) 